\title{
Langerhans cell histiocytosis: a rare case of large-bowel inflammatory lesions
}

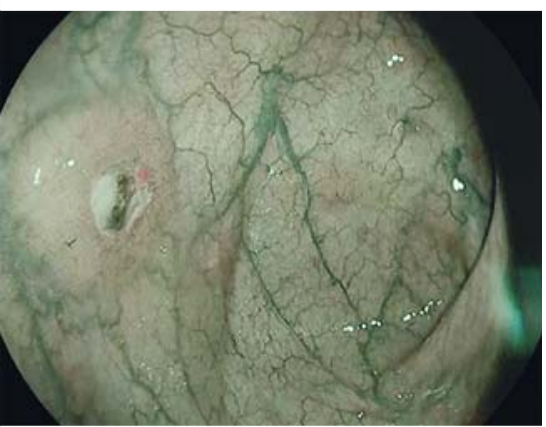

- Fig. 1 High definition endoscopic image with optical enhancement (OE) mode 1 , showing a nodule of $8 \mathrm{~mm}$ with nonadenomatous pit pattern (Kudo II), interrupted vascular pattern, and central aphthous ulcer.

Langerhans cell histiocytosis $(\mathrm{LCH})$ is a rare disease characterized by clonal neoplastic proliferation of Langerhans cells, with typical expression of CD1a, S100 protein, and langerin [1,2]. Gastrointestinal involvement is extremely rare and usually observed in systemic illness with poor prognosis and high morbidity [24].

Here, we report the case of a 48-year old man affected by mucocutaneous Langerhans disease, presenting with severe weight loss, constipation, and nausea. He was previously diagnosed with LCH with pituitary localization in 2002 and underwent treatment with vinblastine, steroids, and mercaptopurine. An esophagogastroduodenoscopy was unremarkable, including duodenal and gastric biopsies. Ileocolonoscopy was performed using a high definition colonoscope with optical enhancement (OE mode) virtual chromoendoscopy (Optivista EPK-i7010 video processor; Pentax, Tokyo, Japan) [5].

During withdrawal, the OE mode 2 was activated to increase the detection of subtle mucosal changes, revealing multiple yellowish nodules of $5-10 \mathrm{~mm}$ in size, with central erosions or aphthous ulcers ( $\downarrow$ Video 1 ). OE mode 1 showed

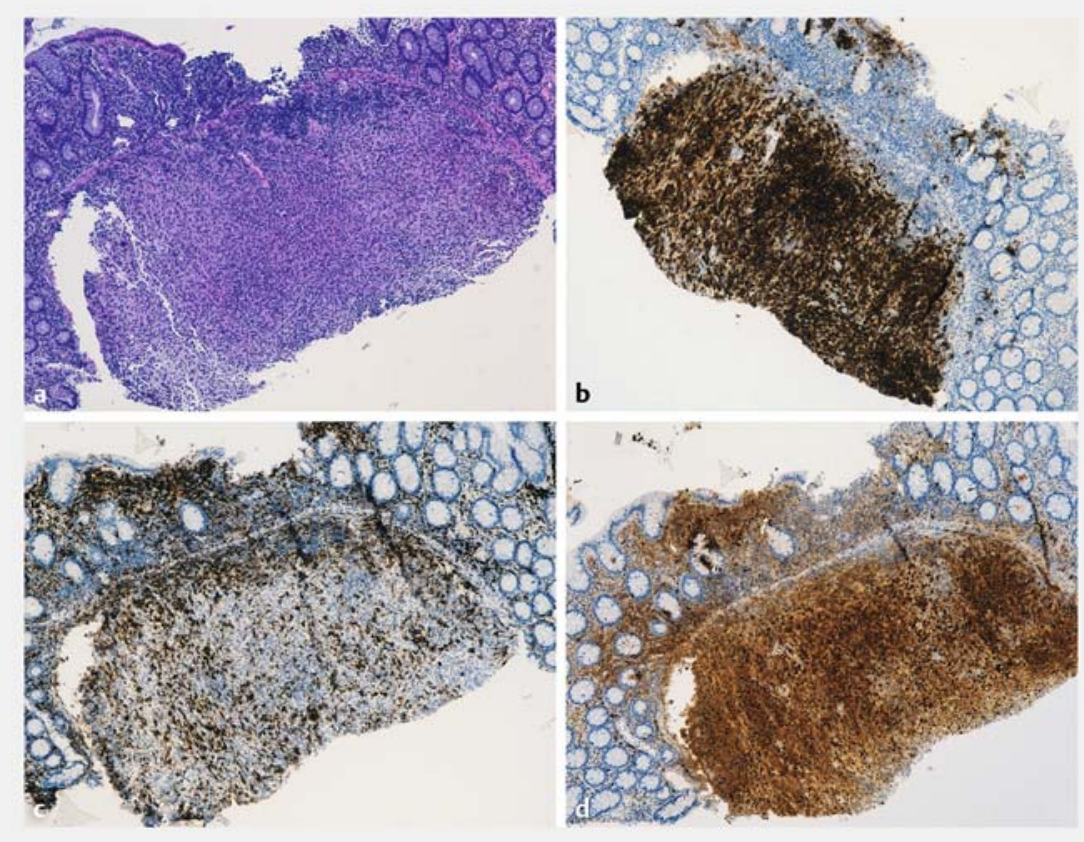

- Fig. 2 Histology of targeted endoscopic biopsies. a Hematoxylin and eosin stain. Diagnostic immunohistochemistry: $\mathbf{b}$ anti-CD1a; $\mathbf{c}$ anti-CD68R; $\mathbf{d}$ S100 protein.

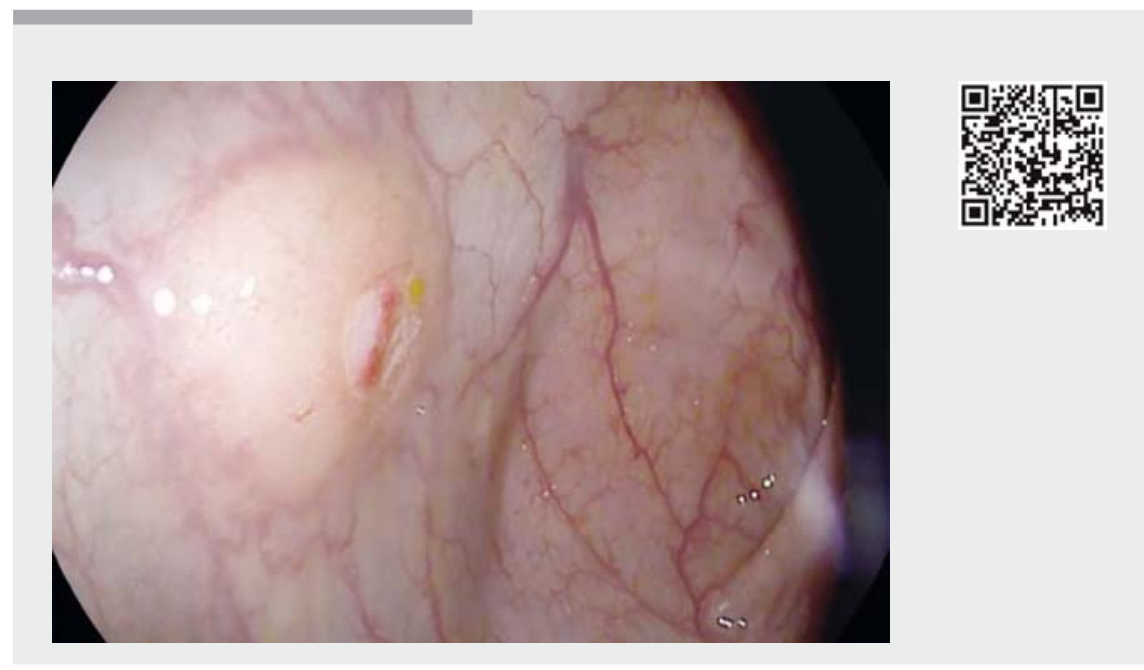

$\checkmark$ Video 1 lleocolonoscopy showing multiple sites of Langerhans cell histiocytosis with high definition optical enhancement (OE mode) chromoendoscopy. OE1-2 mode showed detailed image of a nodule with nonadenomatous pit pattern (Kudo II), interrupted vascular pattern, and aphthous ulcer. 
both the pit and vascular patterns to be clearly characterized as nonadenomatous (Kudo II) and irregular or interrupted (> Fig. 1, \ Video 1).

Histology on targeted biopsy samples demonstrated submucosal proliferation of histiocytes, with abundant eosinophilic cytoplasm, positive anti-CD1a, antiCD68 R, and S100 protein immunohistochemistry, which are pathognomonic for colonic localization of LCH ( $\mathbf{F i g . 2}$ ).

This case is relevant for several reasons. First, we describe an unusual case of gastrointestinal $\mathrm{LCH}$, which unconventionally manifested with symptoms that warranted endoscopic investigations. In addition, we provide for the first time detailed video and image documentation of intestinal LCH to further support clinicians and endoscopists during their everyday practice.

Endoscopy_UCTN_Code_CCL_1AD_2AC

\section{Competing interests}

None

The authors

Beatrice Marinoni ${ }^{1}$, Federica Cavalcoli', Alessandro Del Gobbo' ${ }^{2}$, Helmut Neumann ${ }^{3}$, Emanuela Passoni ${ }^{4}$, Maurizio Vecchi ${ }^{1,5}$, Gian Eugenio Tontini ${ }^{1}$

1 Gastroenterology and Endoscopy Unit, Fondazione IRCCS Ca' Granda Ospedale Maggiore Policlinico, Milan, Italy

2 Pathology Unit, Fondazione IRCCS Ca' Granda Ospedale Maggiore Policlinico, Milan, Italy
3 First Medical Department, University Medical Center Mainz, Mainz, Germany

4 Dermatology Unit, Fondazione IRCCS Ca' Granda Ospedale Maggiore Policlinico, Milan, Italy

5 Department of Pathophysiology and Transplantation, University of Milan, Milan, Italy

\section{Corresponding author}

Beatrice Marinoni, MD

Gastroenterology and Endoscopy Unit, Fondazione IRCCS Ca' Granda Ospedale Maggiore Policlinico, Via della Commenda 12, 20122 Milan, Italy

Fax: +39-02-55033414

beatrice.marinoni@unimi.it

\section{References}

[1] Singhi AD, Montgomery EA. Gastrointestinal tract langerhans cell histiocytosis: a clinicopathologic study of 12 patients. Am J Surg Pathol 2011; 35: $305-310$

[2] Aricò M, Girschikofsky M, Généreau T et al. Langerhans cell histiocytosis in adults. Report from the International Registry of the Histiocyte Society. Eur J Cancer 2003; 39: $2341-2348$

[3] Hait E, Liang M, Degar B et al. Gastrointestinal tract involvement in Langerhans cell histiocytosis: case report and literature review. Pediatrics 2006; 118: e1593-e1599

[4] Bhinder J, Mori A, Kurtz L et al. Langerhans cell histiocytosis of the gastrointestinal tract - a rare entity. Cureus 2018; 10: e2227

[5] Tontini GE, Rimondi A, Neumann $\mathrm{H}$ et al. Usefulness of virtual chromoendoscopy with optical enhancement in everyday clinical practice. Adv Res Gastroentero Hepatol 2017; 7: 555719

\section{Bibliography}

DOI https://doi.org/10.1055/a-0767-6204

Published online: 23.11.2018

Endoscopy 2019; 51: E26-E27

(c) Georg Thieme Verlag KG

Stuttgart · New York

ISSN 0013-726X

\section{ENDOSCOPY E-VIDEOS}

https://eref.thieme.de/e-videos

回回 Endoscopy E-Videos is a free ry access online section, reporting 回钚: on interesting cases and new

techniques in gastroenterological endoscopy. All papers include a high quality video and all contributions are freely accessible online.

This section has its own submission website at https://mc.manuscriptcentral.com/e-videos 